\title{
Digital modeling of geomechanical processes in a structurally heterogeneous geomassif for predicting the parameters of safe underground mining of coal seams
}

\author{
Larisa Pavlova ${ }^{1, *}$ Viktor Fryanov ${ }^{1}$, and Julian Veksler ${ }^{2}$ \\ ${ }^{1}$ Siberian State Industrial University, Novokuznetsk, 654007, Russia \\ ${ }^{2}$ Marco Systemanalyse und Entwicklung GmbH, Koblenz, 56070, Germany
}

\begin{abstract}
A digital model of geomechanical processes in a structurally heterogeneous geo-massif with consideration for the influence of natural and technogenic forces was developed. Based on the results of numerical modeling, the regularities of stress change, convergence of roof and soil rocks, stability of coal pillars between production and development workings were revealed with an increase in the depth of development and the thickness of the interbed rocks within the excavation column of a coal mine.
\end{abstract}

\section{Introduction}

One of the key priorities in the production activities of coal mining enterprises is to ensure safe working conditions for workers while minimizing the risks associated with the process of underground coal mining. The main risks in underground coal mining are the occurrence of a potentially explosive concentration of methane, unpredictable seismic events and geodynamic phenomena resulting from an increase in the depth of development and the complication of mining and geological conditions.

The complexity of mining and geological conditions is characterized by the following features: induced technogenic seismicity within the seismic geodynamic range of a group of mining enterprises; intense manifestations of dynamic phenomena in the form of rock bumps, sudden outbursts of coal, rock and gas with an increase in the development depth to $800 \mathrm{~m}$, and natural methane content up to $30 \mathrm{~m}^{3} / \mathrm{t}$; the negative impact on the operational stability of mine workings of the structural heterogeneity of the rock mass in the form of plicative and disjunctive geological disturbances, replacement of rock layers and coal seams.

The objective of the research is to establish, based on the results of numerical modeling, the regularities of geomechanical processes in a structurally heterogeneous geomassif with a change in the depth of development within the excavation column and the thickness of the rocks in the interbed.

\footnotetext{
${ }^{*}$ Corresponding author: ld_pavlova@mail.ru
} 


\section{Research object and methods}

As an object of research, geomechanical processes in the vicinity of a system of mutually influencing worked out pillars and development workings during the underground development of a suite of adjacent seams of the Erunakovskoye coal deposit in Kuzbass are considered.

A feature of the research object is the unconventional spatial orientation of excavation pillars relative to the elements of the occurrence of coal seams. As a rule, for the development of shallow gas-bearing seams with long fully-mechanized working faces, the longitudinal axes of the excavation pillars in the panels are located along a line close to the strike $[1,2]$. However, according to the results of geodynamic and morphological zoning, it was established [3-5] that the Erunakovsky geological and economic region is characterized by a complex tectonic structure with structural heterogeneity and the presence of a system of tectonic blocks bounded by regional fracture zones. In this regard, in order to exclude a number of reassemblies of the treatment equipment and downtime of the working face when geological fractures of the rupture type are encountered, in practice, the extraction pillars are oriented along the disturbances.

In the article we consider an option for the posinion of excavation pillars to the dip almost parallel to the strike of the disjunctive lines (Fig. 1). When this option is implemented along the length of the pillar, the depth of development varies within 380-665 m. According to the VNIMI Methodological Guide [6-7], the width of stable coal pillars significantly depends on the extraction depth, the length of the longwall face in the pillar, the properties of coal and the rocks enclosing the mined seam, as well as the spatial location of disjunctive disorders.

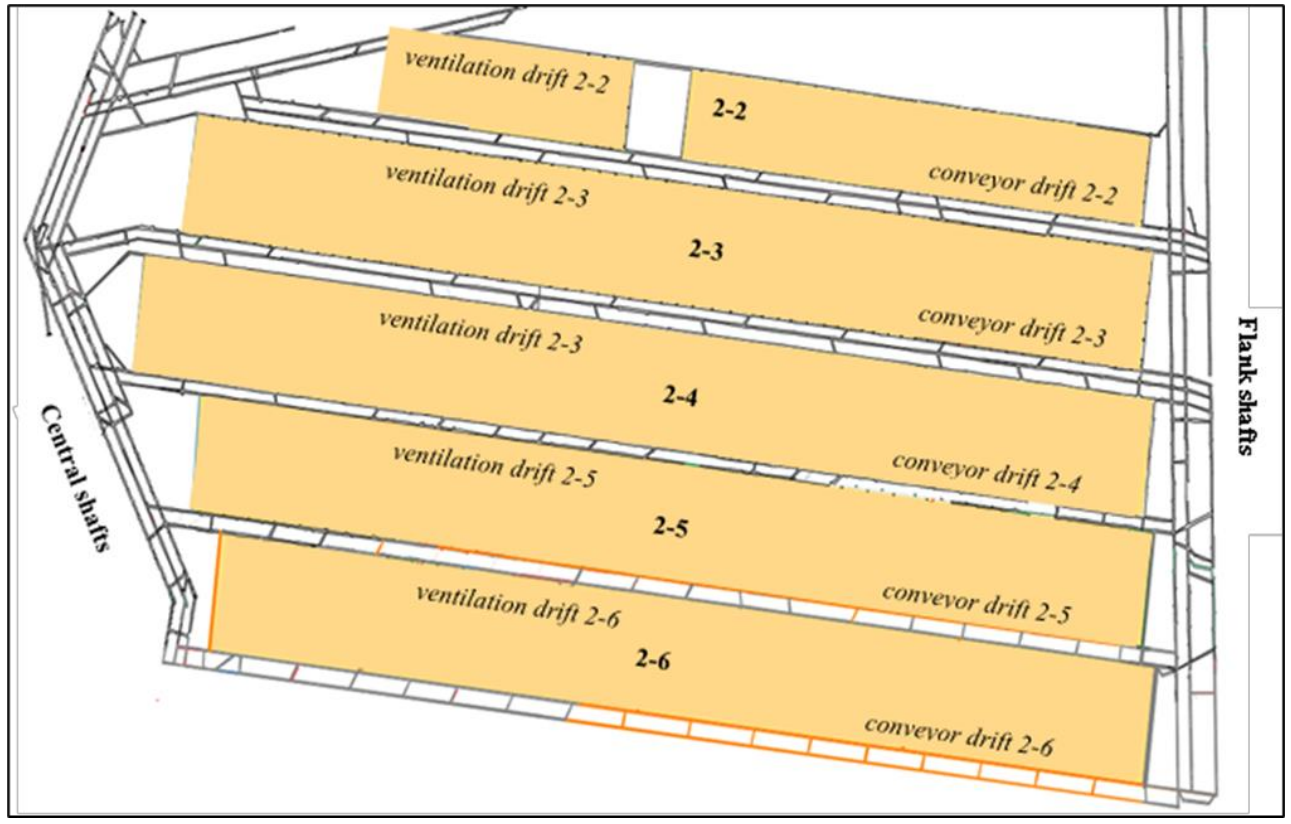

Fig 1. Option of the spatial extraction pillars arrangement in the licensed area of coal mine.

To study geomechanical processes in a structurally heterogeneous geomassif under the technogenic impact of a system of underground workings, a transverse-isotropic nonlinear elastic mathematical model of the environment was adopted, in which the rock mass is idealized as follows: 
- to approximate a continuous displacement function, the mathematical model is idealized by a discrete model, which is built on a set of piecewise continuous functions defined on a finite number of elements;

- the discrete model is assumed to be layered with a transversely isotropic distribution of the strength and deformation characteristics of the layers; the inclined arrangement of layers, the shape and size of underground workings are also taken into account;

- layers are considered viscoelastic; elastic instantaneous deformations, which occur during loading at the initial moment, and creep deformations, developing in time, are taken into account;

- the study area is considered limited: from above by the earth's surface, from below by the height of the overworking zone of the lower seam in the suite, along the strike and dip of the seams - by the maximum dimensions of mine workings; boundary conditions are set on all bounding surfaces of the model in the form of loads or displacements;

- forces distributed throughout the volume of the model are considered as static loads applied at the external and internal boundaries.

The mathematical model is based on the equations of continuum mechanics (equilibrium, continuity of deformations, geometric and physical equations connecting the components of stresses and deformations). To reduce differential equations to a system of linear algebraic equations, the order of which is determined by the number of degrees of freedom of the idealized model, the finite element method is used $[8,9]$.

The stability of workings, sudden outbursts of rocks, coal and gas are associated with the process of deformation and destruction of rocks of the rock mass. Therefore, to predict the stability of coal and rocks in the vicinity of the mined-out area, it is necessary to additionally use a criterion based on one of the strength theories. Strength criteria do not follow from the equations of equilibrium and motion; they are additional conditions when solving problems of limiting equilibrium.

To determine the residual strength of rocks and predict the boundaries of the zone of damaged rocks, the Mohr-Coulomb failure criterion is used, taking into account the change in the stress state of the rock mass under the influence of a system of underground workings, the position of which changes in time and space.

In numerical modeling, the author's software package [10] is used, which is intended for two- and three-dimensional solution of problems of nonlinear elasticity theory by the finite element method.

\section{Results and discussion}

To carry out computational experiments, the following mining-geological and miningtechnical parameters and conditions for mining the upper layer 48 were set (Fig. 1): thickness and angle of dip of the developed seam $-2.1 \mathrm{~m}$ and $11^{\circ}$, respectively; development depth $-200-750 \mathrm{~m}$, width of coal pillars $-30-40 \mathrm{~m}$; thickness of rocks between adjacent seams $-0.5-10.5 \mathrm{~m}$; distance between the working face and the front face entry $-2-10 \mathrm{~m}$; the lateral pressure coefficient in the intact geomass $-\lambda=0.4-1.0$.

Based on the results of numerical modeling, the following geomechanical parameters were analyzed: the width of the coal destruction zone in the seam and host rocks in relation to the residual strength of coal and rocks to the original, vertical and horizontal stresses $(\mathrm{MPa})$, vertical and horizontal displacements of the seam and rocks $(\mathrm{mm})$.

As an example, Fig. 2 shows the isolines of the ratio of the coal residual strength and rocks to the initial strength in the vertical section plane of the cross-section of a coal pillar at depths of development (H) 380, 590 and $665 \mathrm{~m}$. 0.5, 10.5 and $5.5 \mathrm{~m}$, respectively [19]. 
a

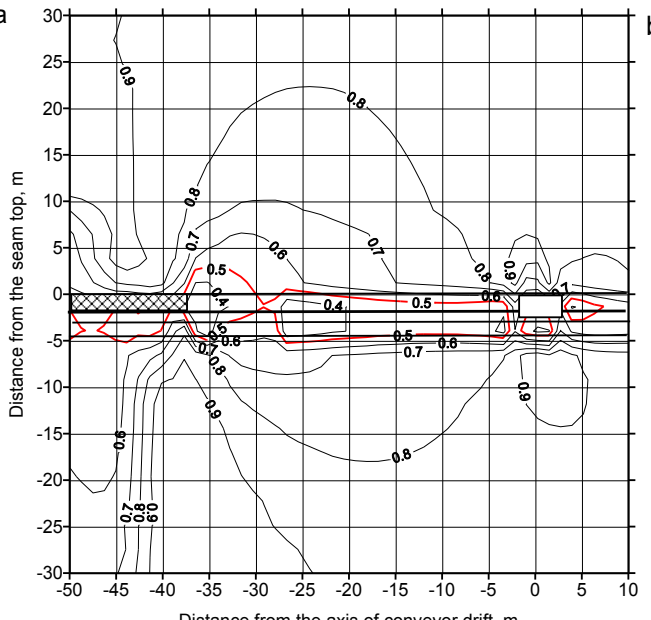

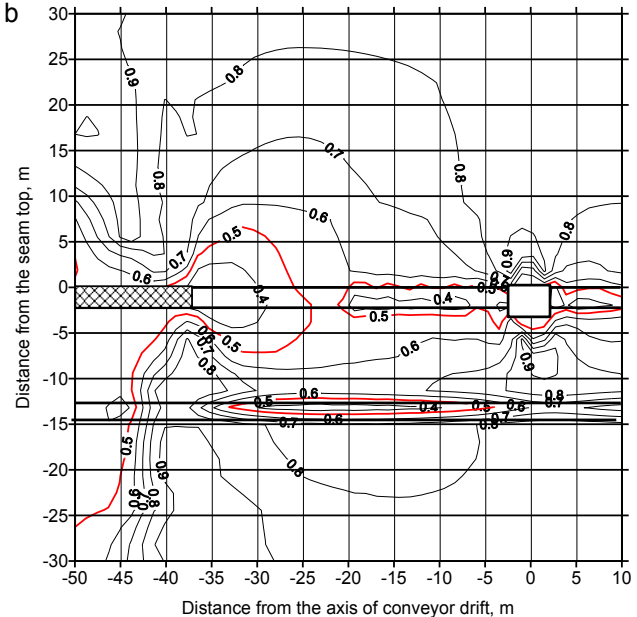

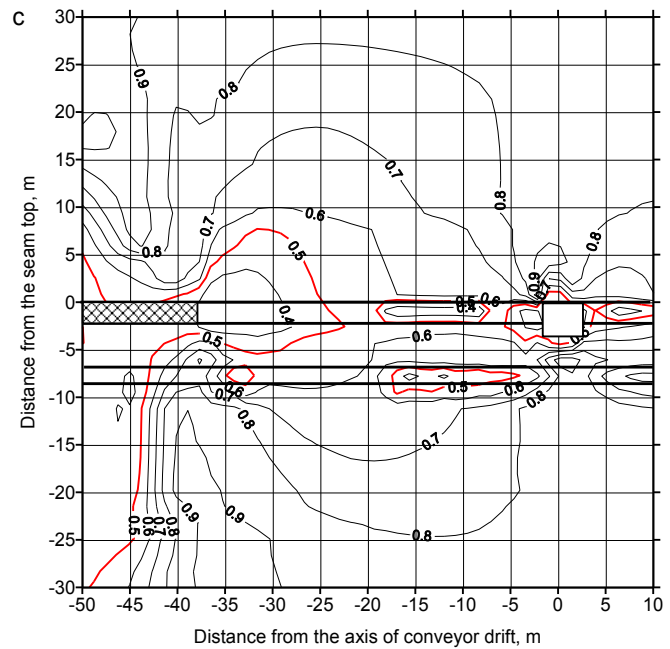

Fig. 2 Isolines of the ratio of residual strength of coal and rocks to the initial strength in the vicinity of the coal pillar: $\mathrm{a}-\mathrm{H}=380 \mathrm{~m}, \mathrm{~h}=0.5 \mathrm{~m} ; \mathrm{b}-\mathrm{H}=590 \mathrm{~m}, \mathrm{~h}=10.5 \mathrm{~m} ; \mathrm{c}-\mathrm{H}=665 \mathrm{~m}, \mathrm{~h}=5.5 \mathrm{~m}$.

After the analysis of simulation results, it was found that almost directly proportional expansion of the destruction zone of the coal seam from the side of the worked-out pillar 48-11 occurs with an increase in the depth of development. In the vicinity of conveyor drift $48-12$, the bearing part of the pillar is reduced to $10 \mathrm{~m}$ at a depth of $665 \mathrm{~m}$.

Fig. 3 shows the distribution graphs of vertical and horizontal stresses for different development depths: 380,590 and $665 \mathrm{~m}$.

Based on the analysis of distribution graphs of vertical and horizontal stresses in the coal seam, it was found that the maximum concentration of vertical stresses occurs in the edge sections of the seam at the boundary with the mined-out space and in the sides of the conveyor drift 48-12 (Fig. 3a). In the soil and the roof of the conveyor drift 48-12, the unloading of rocks and the transition of stresses from compressive to tensile at a distance of 1-2 $\mathrm{m}$ from the mine contour take place. It must be taken into account when choosing the parameters of the drift support. 

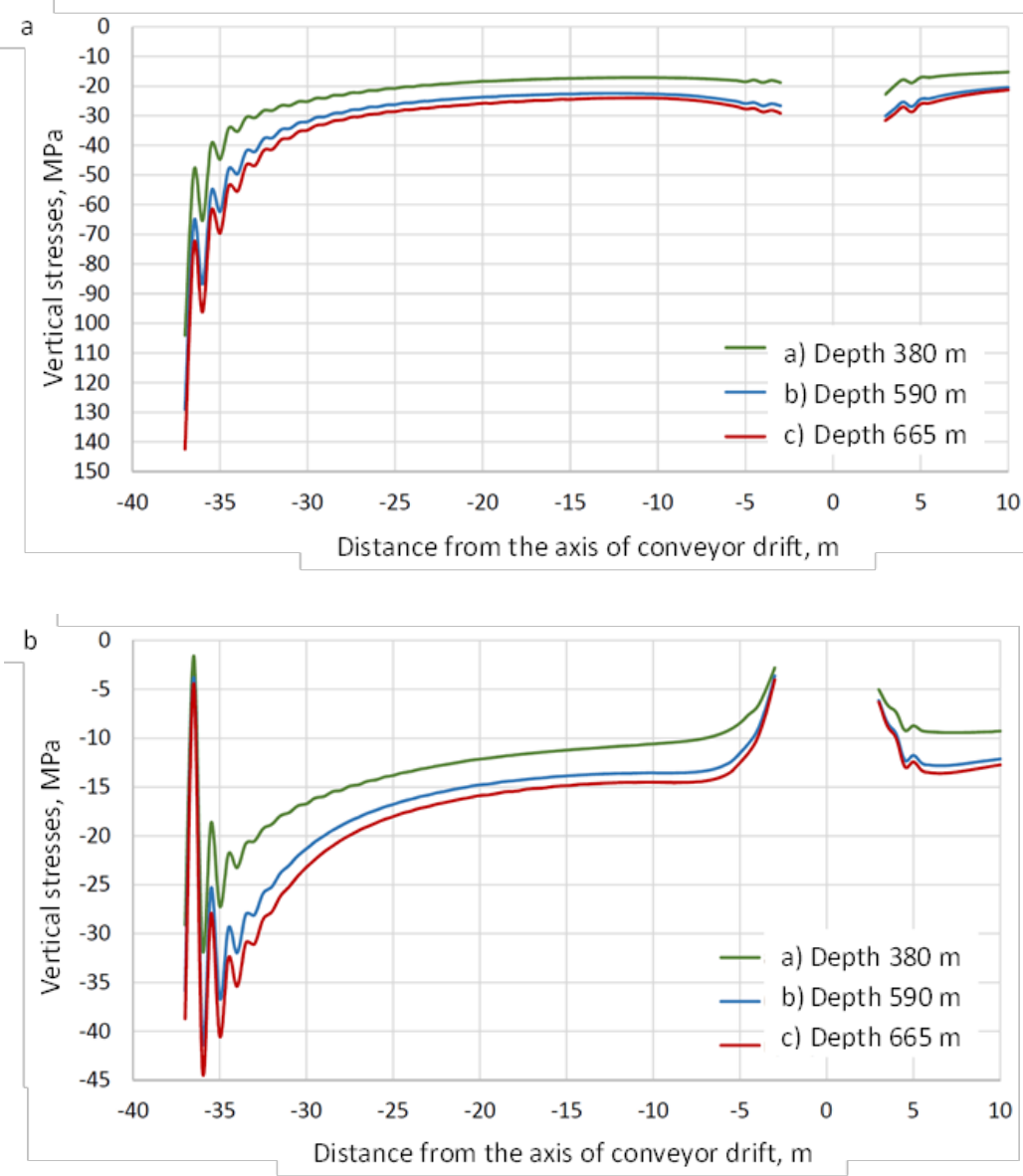

Fig. 4. Distribution graphs of vertical (a) and horizontal (b) stresses (MPa) in the coal pillar $35 \mathrm{~m}$ wide and in the vicinity of a conveyor drift 48-12 at different development depths of seam 48 and a constant lateral pressure coefficient $\lambda=0.5$.

Horizontal stresses in the sides of the development workings are close to zero, which corresponds to the boundary conditions of the design model in the flat-stressed state of the sides of workings (Fig. 3b). In the middle part, the coal pillar is in conditions of volumetric compression, however, at the edge sections of the coal pillar, the horizontal stresses tend to zero, therefore, under the influence of only compressive stresses in these areas, destruction of coal takes place, confirmed by the graphs of the ratio of the coal residual strength to the original, shown in Fig. 2.

\section{Conclusion}

The developed digital model of geomechanical processes in a structurally heterogeneous geomassif makes it possible, based on the results of numerical modeling, to predict the parameters of the stress-strain state of a rock mass under technogenic impact in difficult mining and geological conditions.

Taking into account the predicted geomechanical parameters at the stage of development of project documentation will reduce the risks of dangerous manifestations of 
rock pressure in the process of mining the seam in the form of collapse of roof rocks, coal squeezing from the edge sections of coal seams, heaving of soil rocks.

The study was carried out with the financial support of the Russian Foundation for Basic Research and the Kemerovo Region within the framework of scientific project No. 20-41-420004.

\section{References}

1. A.D. Ruban, Preparation and development of highly gas-bearing coal seams (Gornaya kniga, Moscow, 2010)

2. Yu.A. Korovkin, P.F. Savchenko, Theory and practice of systems of longwall faces (Mining LLC - Cimmerian Center, Moscow, 2012)

3. T.I. Lazarevich, et al., Geodynamic zoning of Southern Kuzbass: monograph (Vesti, Kemerovo, 2006)

4. O.V. Cherkas, Morphostructural zoning of the Kuznetsk depression as a basis for the creation of applied maps: Diss. Cand. technical sciences (Novosibirsk, 2015)

5. V.M. Shik, Geomechanical principles of preparation of mining production in coal mines (Mining LLC - Cimmerian Center, Moscow, 2015)

6. Methodological guide for the selection of geomechanical parameters of the technology of development of coal seams with short faces (VNIMI, SPb, 2003)

7. V.B. Artemiev, et al, Protection of preparatory workings by pillars at coal mines (Mining LLC - Cimmerian Center, Moscow, 2011)

8. A.B. Tsvetkov, L.D. Pavlova, V.N. Fryanov, GIAB, 1, 365-370 (2015)

9. M.O. Eremin, L.D. Pavlova, V.N. Fryanov, AIP Conf. Proc., 2167 (2019)

10. Kornev, L.D. Pavlova, V.N. Fryanov, Cert. of reg. of elect. resource No. 17997, A complex of problem-oriented programs for modeling geomechanical processes in a rock mass during underground mining of coal seams (01.03.2012) 